\title{
Application of chitosan and buriti oil (Mauritia flexuosa L.) in skin wound healing
}

\begin{abstract}
Wound is the breakdown of the structure and normal functions of the integument and its healing process. The wound healing process is common to all tissues and is characterized by three stages: inflammation, proliferation (fibroblast phase) and remodelling. Many substances are used to improve and accelerate this process. A polymer that comes to the attention of researchers is chitosan, which is obtained by the deacetylation of chitin. Another substance that shows good results in the healing process is buriti oil, extracted mainly from the fruit bulb of Mauritia flexuosa L. The main objective of this study is to demonstrate through bibliographical research the effects of chitosan and buriti oil on healing, as well as describing the process of obtaining chitosan and buriti oil and characterizing chitosan and buriti oil. This is an exploratory study where the bibliographical review was used as technical procedure. For the elaboration of the study, we used scientific materials already published, consisting mainly of theses, dissertations, books, articles of scientific journals and annals of scientific congresses, observing the temporal limits between 2000 and 2016. A potential use of chitosan and oil of buriti in the healing of cutaneous wounds since they presented good results in all the phases of tissue repair. Chitosan has been characterized as being biodegradable, biocompatible has free amine groups thus becoming well reactive, the oil has an orange-coloured liquid, rich in carotenoids ( $\beta$-carotene), $\alpha$-tocopherol (vitamin E) And fatty acids. It is expected that this study can serve as a reference for studies on these substances, as well as that they can be used together in order to potentiate their effects on the healing process.
\end{abstract}

Keywords: cicatrisation, chitosan, buriti oil, nano chitosan, vitamin E
Volume 3 Issue I - 2017

Silva RFJ, Pighinelli L

Department in Genetics and Toxicology, Lutheran University of Brazil (ULBRA), Brazil

\author{
Correspondence: Luciano Pighinelli, Post-Graduation \\ Graduate Program in Genetics and Toxicology (PPGGTA), \\ Biomatter Lab, Lutheran University of Brazil (ULBRA), Canoas, \\ Brazil, Email Ipighinelli@hotmail.com
}

Received: February 19, 2017 | Published: May 03, 2017

\section{Introduction}

Wound is the breakdown of the structure and normal functions of the integument and its healing process. It refers to a cascade of events that begins with the trauma and ends with the complete and organized closure of the wound with the scar tissue. ${ }^{1-3}$ The skin is one of the organs most susceptible to injury and needs regeneration to restore its structure and functions, such as protective physical barrier against various environmental stimuli and infections and against excessive water loss..$^{3-5}$ According to Broughton et al., ${ }^{5}$ after the skin damage, the wound process is common to all wounds, regardless of the causative agent, being systemic and dynamic and directly related to the general conditions of the organism. ${ }^{6,7}$ Wound healing is classically divided into three stages:

i. Inflammation

ii. Formation of granulation tissue with extracellular matrix deposition (fibroblastic proliferation) and

iii. Remodelling (including reepithelialisation), (Figure 1). ${ }^{5,8-11}$

In the inflammatory phase the recruitment of leukocytes to the lesion site is observed. In the proliferative phase, a cellular proliferation is observed, mainly of fibroblasts, macrophages and of blood vessels, besides the proliferation and migration of keratinocytes, endothelial cells and reepithelialisations, formed granulation tissue with a great amount of type III collagen, In addition, the collagen fibres have a high affinity for collagen fibres and the collagen content is degraded by proteolytic enzymes that promote tissue remodelling. ${ }^{9,10,12}$ There are many substances in the pharmaceutical market that aims to improve and accelerate the process of cutaneous healing, in addition to many substances extracted from plants that are popularly used to bring benefits to this process. A polymer that comes to the attention of researchers is chitosan, which is obtained by the deacetylation of chitin. Due to its characteristic of presenting free amino groups, chitosan has the capacity to react with several molecules, making the biopolymer with greater availability of pendant groups and it can be used in powder forms, beads or films. ${ }^{13,14}$ According to Ravi Kumar ${ }^{15}$ among the applications of chitosan based biomaterials, it is observed the use as bioadhesive, banding material, material for skin grafting, material for suture and contact lenses, healing agent. As a healing agent, chitosan can inhibit fibroplasia in wound healing and to promote tissue growth and differentiation in tissue culture. Many plants have been and are used as medicinal plants, ranging from simpler local treatments until later in the manufacture of medicines. Many drugs obtained from medicinal plants are used as anti-inflammatory and would healing. ${ }^{12,13,16}$

Mauritia flexuosa L. (buriti), a characteristic plant of the Brazilian cerrado, due to its oleaginous character, has aroused the interest of researchers and industries. Buriti oil, extracted from this plant, has been cited in several studies due to its cicatrizing, antibacterial and antioxidant effects, among others. Many are the popular uses of buriti oil, it is used as a sunscreen due to being able to absorb radiations in the ultraviolet spectrum, reports that due to its high content of $\beta$-carotene, may present antioxidant effect and other bioactive effects that have not yet been investigated, the popular use of buriti oil in topical applications in case of skin burn, provoking immediate relief and aiding in the healing process. ${ }^{17-20}$ One of the oldest concerns of 
medicine is the treatment of wounds. Annually millions of dollars are spent for this purpose all over the world. The present work is justified by the interest in demonstrating studies on the effects of chitosan and its derivatives, in addition to buriti oil on wound healing, to support other studies related to these substances in wound healing. It is initially intended to demonstrate the effects of both chitosan and its derivatives and of buriti oil on cutaneous healing.

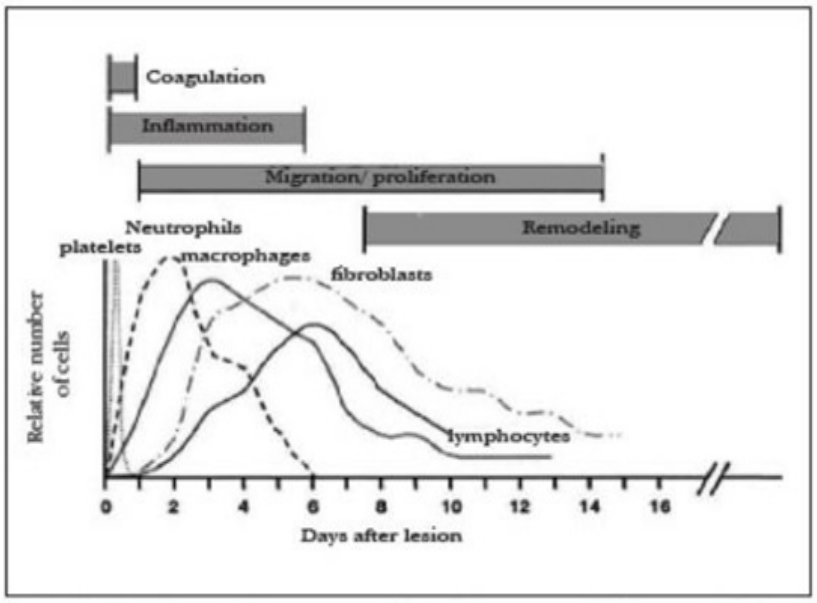

Figure I Stages of healing correlated with immune-cellular specificity.

\section{Discussion}

\section{Chitosan and its derivatives: physical, chemical and bi- ological characteristics}

Chitosan represents a group of partially deacetylated polymers and not a specific chemical entity. The application of chitosan and its characteristics are determined and influenced by its molar mass and the degree of deacetylation. Commercial chitosan's generally having a degree of deacetylation varying from 70 to $95 \%$, with molar mass in the range of $104-106 \mathrm{~g} / \mathrm{mol}^{.21}$ The properties of chitosan are affected by the processing conditions of the material which controls the amount of deacetylation, which is the key process for determining its physical, chemical and biological characteristics. Deacetylation is determined by the amount of free amino groups in the polymer chain and this gives a positive charge to chitosan. The functionality of chitosan is thus directly linked to free amino groups and to hydroxyl. The positive charge allows many electrostatic interactions of chitosan with negatively charged molecules. ${ }^{22,23}$ Chitosan can be characterized by taking into account physical, chemical and biological properties and the physical properties studied are particle size, solubility, density, viscosity and description of their presentations. The chemical characteristics are molecular weight distribution, degree of deacetylation, crystallinity index, $\mathrm{pH}$, water retention value, heavy metal levels and proteins. Biologicals are pyrogenicity, cytotoxicity and biocompatibility. ${ }^{24,25}$

In the chitosan molecule, three types of reactive functional groups are found: one amino group and two hydroxyl groups, one primary and one secondary. The amino group is easily protonated, improving its solubility. The secondary hydroxyl group may also be substituted for the purpose of increasing the solubility of the polymer. The primary hydroxyl can be substituted by chains, forming branched polymers, or even graphitized copolymers. The formation of cross linking or cross linking in chitosan can modify its mechanical properties. This modification is attempted in some scientific works with the aim of improving the mechanical properties of chitosan. Cross-linking or cross-linking can improve the physical properties of polymers. The mixture of chitosan and poly (polyethylene oxide) $\left(\mathrm{C}_{2} \mathrm{H}_{4} \mathrm{O}\right) \mathrm{n}$, for example, may also improve mechanical properties. . $^{1526-28}$ In Brazil, chitosan is marketed as powdered and encapsulated as a source of soluble natural fibre indicated as an aid in weight loss and cholesterol reduction. Despite the use in several areas and the diverse applications of chitosan and its derivatives, there is a limiting factor that is the insolubility of the same in neutral or superior $\mathrm{pH}$. Chitosan is insoluble in water, neutral and alkaline solutions and soluble in acid solutions. In PH lower than 5.5 the amino groups are protonated and the molecule becomes soluble. The solubility of chitosan is related to the amount of protonated amino groups $\left(-\mathrm{NH}_{3}^{+}\right)$in the polymer chain. The higher the number of these groups, the greater the electrostatic repulsion between the chains and the higher the solvation in water. ${ }^{15,29}$

In acidic media the chitosan when solubilized gives rise to viscous solutions, which is related to the amount of amine groups that are protonated, thus, the greater the quantity of these protonated groups, the greater the electrostatic repulsion between the chains and, consequently, the greater the Solvation of the polymer in water, facilitating dissolution. For a given concentration of acid, the degree of protonation depends on the PK of the acid used to solubilize the chitosan. For a protonation degree of approximately 0.5 the chitosan shows solubility in acetic acid or hydrochloric acid solution. The amino groups are protonated in acidic medium and the chitosan becomes soluble in aqueous solutions. However, chitosan precipitates in the aqueous solution when after its dissolution under acidic conditions, the $\mathrm{pH}$ of the solution is increased, reaching values around 6,5 there is a Reduction of the positive charges of amino groups. ${ }^{30-33}$ The solubility of chitosan in water has significant effects with the removal of the majority of the acetylated groups from the chitin structure, which reduces the hydrogen bonds in part because the acetylated groups are rich in these bonds. In addition, it gives the amino groups, which promote positive charges on the macromolecule in an acid medium. Thus, the reduction of hydrogen bonds between the chains combined with the protonated amino groups increases the solubility of chitosan in aqueous solutions. The solubility of chitosan can be associated to several factors: amount of $\mathrm{N}$-acetyl groups $\left(\mathrm{NCOCH}_{3}\right)$ and amine groups $\left(\mathrm{NH}_{2}\right)$, distribution of these groups in the extension of the polymer chain, $\mathrm{pH}$ and ionic strength of the solution..$^{34,35}$

When dissolved in media whose $\mathrm{pH}$ is lower, the amine group present in the chitosan has a pKa of about 6.2 to 7.0 which makes it a polyelectrolyte. Among the few existing natural cationic poly electrolytes are chitin and chitosan. The other natural polysaccharides are either neutral or negatively charged. Chitosan has amino groups that react with some ease, which allows the production of many derivative compounds. The ability of chitosan to undergo structural changes occurs due to the large amount of reactive groups such as hydroxyl and especially amino groups. Due to its properties, chitosan is currently attracting much interest in medical and pharmaceutical applications because of its biocompatibility that allows its use in various medical applications. ${ }^{36,37}$ In biological terms chitosan is recognized as safe and non-toxic by most authors. The toxicity is evidenced only when used for a long period as a food supplement, where it is related as a blockade of the absorption of calcium and fat-soluble vitamins. Studies relate the biological activity of chitosan with its physicochemical properties (water solubility and the size of the chains) and the characteristics of the microorganism membrane. In 
relation to the optimal size of the chain is between $2-200 \mathrm{KDa}$. The $\mathrm{PH}$ influences the antimicrobial activity of chitosan, when the $\mathrm{pH}$ of the medium decreases, increases this activity. ${ }^{38,39}$

\section{Applications of chitosan and its derivatives in the medical area}

Recently, chitosan has aroused the interest of the scientific community due to its great potential of application in the different areas. This fact is observed both for natural forms and for their derivatives. Many chitosan applications are possible because of their versatility and the various chitosan derivatives obtained through chemical reactions through which different functional groups are inserted into their molecules, giving different properties and applications. ${ }^{33,40}$ Chitosan has been investigated in a variety of medical applications including both systemic and local drug delivery, tissue engineering and wound healing. However, its mechanical properties are not yet controllable. As a result, the application of chitosan as a biomedical material is limited to certain areas. But despite this, chitosan has other important properties such as being biodegradable and biocompatible. Furthermore, it is formed by acetyl glucosamine containing units and $\mathrm{N}$-glycosaminoglycans units which react with cross linking agents to produce an interconnected structure with differentiated and often improved properties in the final material. ${ }^{32,41}$ According to several authors, the main applications of chitosan can be observed in the pharmaceutical area (medicines for weight loss, drug mediators, cosmetics, fungicides, tissue regeneration, among others), biomedical (bio-membranes and bone implants), biotechnology and treatment of effluents. Many applications of chitosan have been tested, such as: chromatography, metal chelation, chemical additives for the textile, food, paper, varnish and coating industries and adhesive selective membranes. Other studies of interest are for medical and pharmaceutical applications, because of their intrinsic properties, biocompatibility with human cells, allows their use in various medical applications, such as membranes, bactericides, pharmacological carriers, anticoagulants, microbiological media, among others. In addition, chitosan Is biodegradable as it is metabolized by certain human enzymes, especially lysozyme. . $2,33,35^{2}$

Research on the use of chitosan and its chemical modifications has increased significantly due to its low cost, the potential for application in several areas (biomedical, food, agriculture, water treatment, cosmetics and pharmaceuticals) along with its properties such as biodegradability and low toxicity. Its use as biomaterial is related to its properties as biocompatibility, bio adhesiveness, acting at the opening of the epithelial junction, still observing antimicrobial action, homeostatic balance, stimulation of cell migration and proliferation, activation Of macrophages, promotes the formation of granulation tissues, besides guiding the remodelling of cellular histoarchitecture in wounds. ${ }^{36-38}$ The possibility of being chemically modified the possibility of being processed in different forms (solution, sponges, films, membranes, gel, among others) and being an acid polyelectrolyte are characteristics that make chitosan a polysaccharide of great interest for studies and for various application areas. This leads to several studies on the applicability of chitosan, among which many appear to be related to the antimicrobial effect, presenting good results as inhibitor of the growth of bacteria, fungi and yeasts. In addition, chitosan is metabolized by certain enzymes, especially lysozyme, so it is considered biodegradable. Due to its production in the form of sponges and membranes, its use in dressings and has been growing because it allows a good oxygenation of the tissue and reduces the loss of liquid by evaporation, in addition to avoiding microbial proliferation. Thus a possible promising biological market for chitosan is the regeneration of wounds..$^{36,37,42}$

Research shows a recognized cicatrizing and antibacterial activity of chitosan. This biopolymer has low toxicity and is safe to human and its toxicity is evidenced only when it is used as a food supplement for long periods of time and is related to the blockade of the absorption of calcium and fat soluble vitamins and can cause bone dysfunctions, Vitamin deficiency and growth retardation. Chitosan showed influence in all stages of tissue healing in animal experiments, showed a significant decrease in treatment time, with minimal scar formation. ${ }^{31,35,36}$ Chitosan, due to its properties, is an important biomaterial used in controlled drug delivery systems, with a wide variety of administration routes, such as: oral, nasal, ocular, transdermal, vaginal and dressing. According to their physical structure and form of obtaining chitosan, as: nanoparticles, microspheres, membranes, films, sponges and others. Other areas of medical applications are in ophthalmology and nephrology, chitosan can be used as contact lenses, or protective film in the recovery of tissue submitted to intraocular surgeries or in cases of chronic corneal impairment, as it does not require removal, because it is biodegradable. For patients with renal insufficiency the application of chitosan membrane helps in renal filtration. By its fungicidal, bactericidal and cicatrizing immune system activator, chitosan is used as an artificial skin for the regeneration of epithelial tissue, repairing and normalizing the damaged tissue. ${ }^{33,34,43}$

In the food industry, chitosan is used for the formation of biodegradable films, recovery of by-products, purification of water, clarification of juices, emulsifier of aromas, antioxidant, emulsifying agent and stabilizer, highlighting its effectiveness in preserving the microbiological quality of the and the effect of chitosan coatings on the shelf-life of fish. Studies show that chitosan as adsorbent of metal ions, use this because of its low cost, since it is a waste from the fishing industry is biodegradable and when comparing its adsorbent power to that of silica, this is very close. Besides these factors, others such as the absence of toxicity, biocompatibility and hydrophilicity, chitosan has been widely used in studies to treat effluents, being used as a chelating agent of metals, as flocculants, as adsorbent of dyes, adsorbent of metallic anions and others. ${ }^{35-37}$ Chitosan has affinity for all metal ions of group II and III and cations of metals and transition, fact observed in several studies. In the literature we can find several works that use chitosan and chitosan chemically modified for the complexation of metallic ions. Metals react with the amino group of chitosan, forming stable complexes by coordination bonds. The nitrogen electrons present in the amino group are stabilized by bonds with metal ions. Some hydroxyls present in chitosan can function as electron donors and consequently are involved in the formation of this complex. This type of complex, where $\mathrm{M}+2$ is bound to amine groups, has a charge transfer band and this can also be attributed to the great interaction of the metal with the polymer. ${ }^{43,44}$

\section{Chitosan in wound healing}

Chitosan among the most studied natural polymers for skin repair. Excipients for consistency of creams, adhesive matrices, spongetype dressings, hydrogels, membranes and adhesives may be used as gelling agents in transdermal delivery systems. Many other authors report that because of their characteristics as being biodegradable, adhesive, non-toxic, bacteriostatic, fungi static, haemostatic and bactericidal, chitosan is an excellent material for the treatment of 
wounds. Membrane wound dressing is an alternative to the use of topical preparations for treating them, seeking to replace lost skin function, protect the wound from loss of fluids and proteins, prevent bacterial invasion and reduce mechanical stress, Improving and stimulating healing. Chitosan in its different forms has been studied as a low cost option for wound dressing. In addition to covering and protecting the wound from external agents, chitosan can also be used as a support for controlled drug release. ${ }^{43,44}$ Chitosan is degraded by the enzyme lysozyme, which is present in tissues, organs and body fluids of mammals, including lacrimal fluid with contents above $1 \%$. Some biological properties such as antimicrobial and healing activities have been attributed to fragments (oligosaccharides) resulting from the enzymatic degradation of chitosan. The products of the enzymatic degradation of chitosan are oligomers of N-acetyl-D-glucosamine, which, besides having healing properties, antimicrobial, are totally absorbable by the organism. ${ }^{33,45}$

Chitosan allows rapid blood clotting and has gained US approval for use in bandages and other haemostatic agents. The product reduces blood loss compared to gauze and increases patient survival. These products were sold to the United States Army which has already made use of the bandages. Chitosan is hypoallergenic and has natural antibacterial properties. Among the applications, it has also been used in haemodialysis membranes. ${ }^{35,46}$ Many authors have already proposed and studied the application of chitosan in wound healing. Chitosan membranes are not cytotoxic when tested with fibroblasts, the human wounds treated with chitosan membranes heal faster, the chitosan oligosaccharides from their enzymatic degradation have a stimulating effect on macrophages and attract neutrophils to the lesion site. The action of chitosan-based dressings on acute and chronic skin wounds, verified in studies, demonstrates its performance in all stages of the healing. Porous membranes of chitosan provide excellent permeability to oxygen, control water loss through evaporation and promote drainage of exudate from the wounds. ${ }^{44-47}$ The chitosan membrane, in the form that was elaborated and in the experimental conditions of its study, intensified the formation of the granulation tissue, highlighting potential reparative effect. There was no interference in the healing time of the cutaneous wounds of horses, allowing the conduction of new studies to verify their effects in the different stages of cicatrisation or as biomaterial, associated to drugs for controlled release, growth factors and cell therapy. In veterinary medicine, chitosan has found good results in improving the function of polymorphonuclear leucocytes and macrophages, promoting the granulation and organization of open wounds and is therefore important in healing them. This effect is related to the activation of growth factors. ${ }^{45,47,48}$

Chitosan is able to promote adequate formation of granulation tissue, due to the correct deposition of collagen fibres, leading to correct repair of lesions on the skin. The main biochemical effects of chitin and chitosan the activation of fibroblasts, production of cytokines, accelerates the migration of macrophages and stimulation of type IV collagen synthesis. In the studies of Muzzarelli et al., ${ }^{33}$ a large number of patients with traumatic wounds were treated with chitosan and glycolato dressings and satisfactory results were observed in all cases. So many studies emphasize the combination of chitosan with other materials to improve its effect on healing. Another studies, combined chitosan with other substances and observed acceleration of wound closure and thus, faster healing. ${ }^{32,33,44,45,47,49}$ The higher the degree of deacetylation, the greater the efficiency of chitosan in the modulation of human fibroblasts mitogenesis and the greater the cell adhesion and proliferation, both for keratinocytes and fibroblasts, a fact observed in the study by Ueno et al. ${ }^{35}$ and Chatelet et al..$^{50}$ This increased cell adhesion and proliferation was associated with the fact that, even at neutral $\mathrm{pH}$, there are still cationic sites in chitosan chains, allowing electrostatic interaction with negative charges on the surface of the cell membranes. The antimicrobial activity is believed to be due to the interaction of the amino-positive groups of the glucosamine units with the negative components of the cell walls of the bacteria, suppressing the biosynthesis. It is also observed that chitosan interrupts the transport of nutrients through the cell wall and causes the leakage of cellular organelles, accelerating the death of the bacteria. Another mechanism studied is the penetration of chitosan of low molar mass in the cell, which binds to DNA, inhibiting transcription and translation. ${ }^{46,50,51}$

The bactericidal properties of chitosan with chondroitin sulphate, noting that the increase in the proportion of chondroitin sulphate caused an increase in the number of bacteria, so that the bactericidal effect would be caused only by chitosan. Several authors have investigated the antimicrobial activity of chitosan and the microorganisms mentioned are: Candida albicans, Enterobacter cloacae, Enterococcus faecalis, Escherichia coli, Klebsiella pneumoniae, Streptococcus pyogenic, among others. The antimicrobial activity of chitosan and its derivatives against different groups of microorganisms such as bacteria, yeasts and fungi has received considerable attention. Many studies have shown that the surface charge of chitosan changes considerably as a function of the $\mathrm{pH}$ of the solution in which it is immersed, generating a positive charge that attacks the cell wall of the microorganisms. When the amino groups of chitosan come into contact with the physiological fluids, they are probably protonated and bind to anionic groups of the microorganisms, resulting in agglutination of the microbial cells and inhibition of growth. ${ }^{47,49,52,53}$

Bactericidal, bacteriostatic and fungicidal activities play a role in the healing process, as it has been proven that bandages and dressings can lead to cytotoxicity, delaying the tissue repair process. As chitosan has antibacterial effects, there is no need to use other substances during wound. Some studies demonstrate the potent topical analgesic action of both chitin and chitosan. The main analgesic effect of chitosan occurs due to the capture of acid hydrogens released at the site of inflammation by ionization of the amino group to $\mathrm{NH}_{3}^{+}$. The use of chitosan-based products for the regeneration of tissues such as artificial fur, ${ }^{16}$ hydrogels, ${ }^{38}$ films, ${ }^{2}$ sponges ${ }^{54}$ and dressings ${ }^{52}$ due to their ability to assist in the fight against infections. ${ }^{44,50,54,55}$

\section{Buriti (mauritia flexuosa I.) general characteristics of the tree and the fruit}

The Mauritia flexuosa L., popularly known as miriti, moriti, carandá-guassú, palm-do-brejo, buriti-do-brejo, buriti, belonging to the family Arecaceae is a plant of Amazonian origin diffused in the cerrado and has a wide distribution between Peru , Colombia and Brazil, in the states of Amazonas, Bahia, Goiás, Pará, Piauí, Minas Gerais, Ceará, Tocantins, Maranhão and São Paulo. The buriti is a smooth-stemmed palm tree measuring $23-50 \mathrm{~cm}$ in diameter and $2.8-35 \mathrm{~m}$ high, its leaf can be up to $5.83 \mathrm{~m}$ long and with 120 to 236 segments, the fruit is orange-coloured covered with scales Corneas reddish brown. ${ }^{56}$ The studies show that the word buriti came from the tupi-guarani (Indian language), dembyriti palm tree that emits liquid and after modifications and regional changes of this word came the term buriti, which is very common in almost all the Brazilian territory, 
giving names to streets, Cities, farms, among others. There are also those who know it by miriti, coconut tree buriti, carandá guaçu, carandaí-guaçu, muriti, moriti, boriti, palm tree buriti, palm-of-brejos, mariti, bariti, meriti, ite, aeta and morichi, Aguaje, carandaí-guazu, ideuí and canaguchi.

The "Tree of Life" as it is known Mauritia flexuosa L. (Buriti), due to its diversity of uses, is one of the plants symbolic of the Brazilian cerrado. In addition to providing raw material for medicines, food, handicrafts and shelter, buriti plays an important role in the maintenance of springs and watercourses in the Cerrado, thus being fundamental to the ecosystem and to the populations living in it. Pulp extracted from buriti fruit is a product widely marketed and consumed by rural and urban populations in much of the country. The exotic flavour of the buriti is gaining more and more space in ice cream shops in the big cities, pointing to a promising market that will demand more and more organization of the productive communities and also attention of the public managers to the viabilization of the extractive activity. Buritizeiro has a great cultural and economic value for the peoples of the regions where it is developed, since it provides a huge variety of products and uses, supporting or supplementing the income of several families, especially the Brazilian cerrado. It occurs in places where the soil is soaked, even in the dry season, thus being a source of clean water for people and animals. ${ }^{56,57}$ Buriti (Mauritia flexuosa) is a plant typically found in the Amazon rainforest and is considered one of the most abundant palm trees in the country. They occur throughout the Amazon, Central Brazil, Bahia, Ceará, Maranhão, Minas Gerais, Piauí and São Paulo in the low areas of open and closed forests, on poorly drained, swampy or flooded soils. The buriti palm is one of the most important native species with economic potential in Latin America, although it also presents anthropological and ornamental importance to the producing regions..$^{58-60}$

Mauritia flexuosa and a dioecious palm with flabelliform leaves when adult, are characterized by being tall, with up to $30 \mathrm{~m}$ and 20 $50 \mathrm{~cm}$ in diameter, of solitary and smooth stem. In the Cerrado, it flourishes in the months of March to May and presents fruits almost all year. The reddish-brown, oblong-globose fruits, measuring five centimetres by four centimetres, pericarp covered by overlapping scales of about six millimetres, meaty mesocarp, usually containing a seed. The seeds of M. flexuosa can be classified as recalcitrant and the emergence of the seedlings occurs between three and four months after sowing. Seedlings are slow growing and fruit production can take seven to eight years. The buriti growth is slow, this palm has a single trunk and presents difficulties for vegetative reproduction, since it demands a great amount of water for its satisfactory development. In order to be cultivated in crops, this species presents great limitations and sustainable management techniques should be encouraged and improved, as the areas of buriti occurrence are considered Permanent Protection Areas (APP), which is a place where all forests must be maintained and other forms of natural vegetation and should not be modified to other types of occupancy. ${ }^{60-62}$ The buriti (Mauritia flexuosa L.) popularly known as Canada-guaçu, smell of coconut, miriti, palm of the marsh, among others, is a palm tree of the family Arecaceae, native of Brazil, with great socioeconomic potential. Normally, its occurrence is associated to areas that are periodically or permanently flooded or poorly drained, sometimes close to rivers, along forests of galleries and savannah (Central Brazil and Venezuela). The fruit (Figure 2) is enveloped by a pericarp (or bark) composed of reddish brown triangular scales and is elliptical to oval. The mesocarp (pulp or mass) is thin, yellowish or orange, fleshy and oily. The pulp has a pH of about 4.7 and is 20 times richer in vitamin A than carrots, as well as being very rich in oils, especially in pulp and shell, in proteins and in vitamins $\mathrm{C}$ and $\mathrm{E} .^{63}$

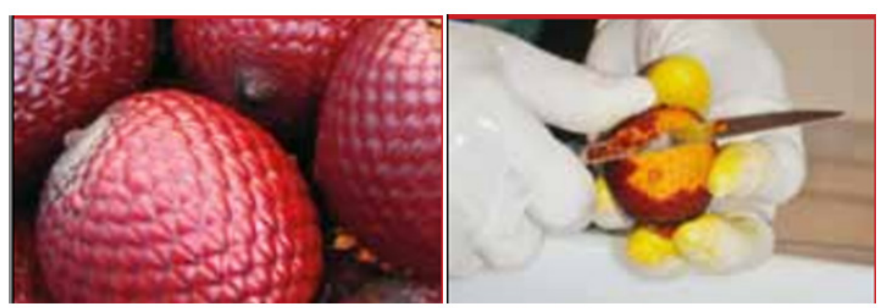

Figure 2 General aspects of buriti fruit.

Some physical characteristics of the fruits of the buriti are: fruit weight of 15 to $75 \mathrm{~g}$, fruit length of 3 to $7 \mathrm{~cm}$, fruit diameter of 2 to $5 \mathrm{~cm}$, seed weight of 4 to $24 \mathrm{~g}$, Moisture content of the pulp from $50 \%$ to $70 \%$, seed moisture content $57 \%$, moisture content of the fruit $69 \%$ to $75 \%$ and percentage of pulp in the fruit from 10 to $37 \%$. Pianovski, ${ }^{64}$ cites buriti as one of the main sources of pro-vitamin A found in Brazilian biodiversity. In the present study, the total weight of the pulp of the buriti was $62.93 \%, 8.25 \%$ of total carbohydrates, $5.17 \%$ of these total dietary fibres, $2.10 \%$ of the protein with predominance of amino acids Sulphur and tryptophan. The lipid fraction of the pulp corresponds to $13.85 \%$, with oleic acid as the main fatty acid. It is also observed $0,94 \%$ of total minerals predominating the elements $\mathrm{K}, \mathrm{Ca}$, $\mathrm{Na}, \mathrm{Mg}, \mathrm{Fe}, \mathrm{Mn}, \mathrm{Zn}, \mathrm{Cu}, \mathrm{Se}, \mathrm{Cr}$ and I. The chemical composition of fruit pulp, respectively, found values for moisture contents of $50.50 \%$ and $62.93 \% ; 3.7 \%$ and $2.1 \%$ proteins; Lipids $19.0 \%$ and $13.85 \%$; Ash $0.6 \%$ and $0.94 \%$; Carbohydrates $26.2 \%$ and $8.25 \%$. This fruit also offers high nutritional value when compared to other fruits. According to Pianovski, ${ }^{64}$ buriti pulp has levels of B vitamins (B1, B2 and PP) equivalent to or higher than other fruits such as avocado, banana and guava, reported that the fruit has some minerals in important amounts, such as calcium, iron and selenium. ${ }^{63-66}$

\section{Buriti oil in wound healing}

Buriti oil has many applications in the cosmetics and food industries. In folk medicine it is used against burns, provoking immediate relief and rapid healing. Based on the high concentration of oleic acid and the presence of carotenoids and vitamin $\mathrm{E}$ in the form of $\alpha$-tocopherol, it helps in the process of tissue repair by the binding to the free radicals produced in the wound. In addition, the high concentration of fatty acids is important in the formation of scar collagen fibres, because it promotes cell proliferation and accelerates the tissue granulation process ${ }^{64,67,68}$ An important substance found in buriti oil is ascorbic acid, also known as vitamin $\mathrm{C}$, is a water soluble vitamin, synthesized by plants and by almost all animals except humans. Vitamin $\mathrm{C}$ is essential for health, as it plays a fundamental role in the development and regeneration of muscles, skin, teeth and bones, in the formation of collagen, in the regulation of body temperature, in the production of various hormones and in metabolism in general. Vitamin $\mathrm{C}$ can also act as a synergist in the regeneration of primary antioxidants. In relation to the ascorbic acid and poly-phenol contents in the buriti pulp contains vitamin $\mathrm{C}$ contents close to those of orange and lower than those found in cabbage. For the poly-phenols, it was verified that the pulp of buriti contains higher value than the one found in the literature for carrots and cabbage. ${ }^{65,67,69}$

Because it contains ascorbic acid, which has the function of hydroxylating collagen, besides being essential to stimulate dermal 
fibroblasts and catecholamine biosynthesis, buriti oil has good results on the healing process. In addition to being an antioxidant with an important function of neutralizing free radicals, it repairs the wall of the blood vessel and also plays a fundamental role in the immune defense. Another function of ascorbic acid is to decrease the number of macrophages, thus contributing to a lower production of free radical and cytotoxic material. The buriti oil presents significant amounts of carotenoids, vitamin E ( $\alpha$-tocopherol), unsaturated fatty acids such as oleic and linoleic acid. These carotenoids and vitamin $\mathrm{E}$ in the form of $\alpha$-tocopherol, the buriti has a beneficial effect on the tissue repair process by binding to the free radicals produced in the wound and, thus, protect the cell membrane from lipid peroxidation and provide protection to the skin. Antioxidant compounds such as beta-carotenoid and vitamin $\mathrm{E}$ exert a protective effect on the new cells to form in the regenerating lesion. It is also observed that the high concentrations of unsaturated fatty acids have an important role in tissue regeneration, being an important element for the formation and deposition of collagen fibres on the scar, besides promoting cell stimulation and proliferation. ${ }^{65,67,68}$

The buriti oil has high concentration of oleic acid and presence of carotenoids and vitamin $\mathrm{E}$ in the form of $\alpha$-tocopherol, which according to several authors helps in the process of tissue repair by the connection to free radicals Produced in the wound. In addition, the great concentration of fatty acids is important in the formation of the collagen fibres of the scar, due to promote cell proliferation and accelerate the process of tissue granulation. Buriti oil has the function of lubricating and regenerating the hydrolipidic barrier of the skin that is frequently subjected to lesions. Together, antioxidant compounds, such as beta-carotenoids and vitamin E, exert a protective effect on the new cells to form in the regenerating lesion. It is observed that high concentrations of unsaturated fatty acids have an important role in tissue regeneration, being an essential element for the formation and deposition of collagen fibres on the scar, besides promoting cell stimulation and proliferation. ${ }^{56,59,60,63}$ The in vitro antibacterial and healing activity of buriti oil was performed by Batista et al. ${ }^{58}$ with greater sensitivity to buriti oil in B. subtilis, K. pneumoniae and S. aureus and the healing activity assay in the Fourteenth day in the oil-treated group, a significant reduction in macrophage counts was observed and a significant increase in fibroblast and collagen fibre. The results allowed us to conclude that buriti oil (M. flexuosa) showed antibacterial activity in vitro in both gram-positive and gram-negative bacteria and was efficient in the healing process of skin wounds in Wistar rats, since it promoted a Good result in the group treated with buriti oil in relation to the control group. ${ }^{70,71}$

\section{Conclusion}

Taking into account the literature, a potential use of chitosan, nanoparticles and buriti oil in the regenerative medicine focus in wound healing, showed a very big potential, was observed, since they showed (both biomaterials) good results in all phases of tissue repair Antimicrobial effect, cell migration and proliferation stimulation, promotion of granulation tissue formation, among others, of chitosan and its derivatives, as well as buriti oil were observed. Chitosan is obtained by a deacetylation process of chitin found mainly in the shells of crustaceans and very important characteristics of chitosan and nano chitosan were: biodegradable, biocompatible, free amine groups. Buriti oil is extracted mainly from the fruit of M. flexuosa L. It can be made by the decoction method (fruit pulp, by pressing method (fruit pulp) and becoming well reactive, the oil has an orange-coloured liquid appearance, rich in carotenoids ( $\beta$-carotene), $\alpha$-tocopherol
(Vitamin E), elements $\mathrm{K}, \mathrm{Ca}, \mathrm{Na}, \mathrm{Mg}, \mathrm{Fe}, \mathrm{Mn}, \mathrm{Zn}, \mathrm{Cu}, \mathrm{Se}, \mathrm{Cr}$ and I and fatty acids. It is hoped that this study may serve as a reference for studies on these substances, as well as that they may be used together in order to potentiate their effects on the healing process.

\section{Acknowledgements}

None.

\section{Conflict of interest}

The author declares no conflict of interest.

\section{References}

1. Airoldi C. A relevante potencialidade dos centros básicos nitrogenados disponíveis em polímeros inorgânicos e biopolímeros na remoção catiônica. Quím Nova. 2008;31(1):144-153.

2. Antonov SF, Kryzhanovskaya EV, Filippov YI, et al. Study of wound-healing properties of chitosan. Russ Agricult Sci. 2008;34(6):426-427.

3. Baum CL, Arpey CJ. Normal cutaneous wound healing: clinical correlation with cellular and molecular events. Dermatol Surg. 2005;31(6):674-686.

4. Odilio BGA, Da Silva VL. Caracterização estrutural e da capacidade de absorção de Água em filmes finos de quitosana processados em diversas concentrações. Polímeros. 2003;13(4):223-228.

5. Broughton G, Janis JE, Attinger CE. Wound healing: na overview. Plast Reconstr Surg. 2006;117(7Suppl):1eS-32eS

6. Park J, Barbul A. Understanding the role of imune regulation in wound healing. Am J Surg. 2004;187(5A):11-16.

7. Thakare VM. International Standard Serial Number, Promotion of $\mathrm{Cu}-$ taneous Wound Healing by Herbal Formulation Containing Azadirachta indica and Cynodon dactalon extract in wistar rats. International Journal of Pharmaceutical Research \& Development. 2011;3(4):80-86.

8. Vinoth kumar P, Amala bricey A, Thamari selvi VV, et al. Antioxidan effect of green tea extract in cadmium chloride intoxicated rats. Advances in Applied Science Research. 2010;1(2):9-13.

9. Luiz Cláudio Candido. Livro do Feridólogo: tratamento clínico cirúrgico de feridas cutâneas agudas e crônicas. Brazil: Candido L C Santos 2006 pp. 646.

10. Cardoso CR, Souza MA, Ferro EA, et al. Influence of topical administration of n-3 and n- 6 essential and n-9 nonessential fatty acids on the healing of cutaneous wounds. Wound Reg. 2004;12(2):235-243.

11. De Mesquita RMGR. Rutiene Maria Giffoni Rocha de. Caracterização do tratamento de feridas complexas em um Hospital Geral, Boa Vista, Africa; 2013.

12. Clark RAF. Wound repair. Kumar Robbins Cotran. 7th ed. Pathologic Basis of Disease, Saunders, Canada; 2005. 112 p.

13. De Rosso VV, Mercadante AZ. Identification and quantification of carotenois by HPLC-PDA-MS/MS, from amazonian fruits. $J$ Agric Food Chem. 2007;55(13):5062-5072.

14. Gurtner GC, Werner S, Barrandon Y, et al. Wound repair and regeneration. Nature. 2008;453(7193):314-321.

15. Ravi Kumar MNV. A review of chitin and chitosan applications. Reactive and Functional Polymers. 2000;46(1):1-27.

16. Mandelbaum SH, Di Santis EP, Mandelbaum MHSA. Cicatrisation: current and auxiliary resources-Part 1. An Brás Dermatol. 2003;78(4):393410. 
17. Mendonça R, Coutinho Netto J. Aspectos celulares da cicatrização. Anais Brasileiros de Dermatologia. 2009;84(3):257-262.

18. Ratner AJ, Lysenko ES, Paul MN, et al. Synergistic proinflammatory responses induced by polymicrobial colonization of epithelial surfaces. Proc Natl Acad Sci USA. 2005;102(9):3429-3434.

19. Santos JS. A Rosa Mosqueta no tratamento de feridas abertas: uma revisão. Revista Brasileira de Enfermagem. 2009;62(3):457-462.

20. Santos VLCG. Avanços tecnológicos no tratamento de feridas e algumas aplicações em domicílio. In: Duarte YAO, et al. editors. Atendimento Domiciliar um enfoque gerontológico. São Paulo Atheneu, Brazil; 2000.

21. Pinto LAA. Quitina e Quitosana obtidas de rejeitos de pescado e aplicações no tratamento de efluentes (Capítulo 4(8): 435-444). In: Gonçalves AA, editor. Tecnologia do pescado: ciência, tecnologia, inovação e legislação. Atheneu, São Paulo, Brazil; 2011.

22. Alemdaroglu C, Degim Z, Celebi N, et al. An investigation on burn wound heling in rats with chitosan gel formulation containing epidermal growth factor. Burns. 2006;32(3):319-327.

23. Pillai CKSL, Sharma CP. Chitin and chitosan polymers: Chemistry, solubility and fiber formation. Prog Polym Sci. 2009;34(7):641-678.

24. Rinaudo M. Chitin and chitosan: Properties and application. Prog poly msci. 2006;31(7):603-632

25. Bezerra AM. Síntese e avaliação físico-química e biológica de derivados de quitosana de alta e baixa massa molecular. São Paulo, Brazil; Universidade de São Paulo Faculdade de Ciências Farmacêuticas; 2011.

26. Kim IY, Seo SJ, Moon HS, et al. Chitosan and its derivatives for tissue engineering applications. Biotechnol Adv. 2008;26(1):1-21.

27. Khor E, Lim LY. Implantable applications of chitin and chitosan. Biomaterials. 2003;24(13):2339-2349.

28. Kim IY, Seo SJ, Moon HS, et al. Chitosan and its derivatives for tissue engineering applications. Biotechnology Advances. 2008;26(1):1-21.

29. Kumar MN, Muzzarelli C, Muzzarelli C, et al. Chitosan chemistry and pharmaceutical perspectives. Chem Rev. 2004;104(12):6017-6084.

30. Kumar PV, Bricey AA, Selvi VV. et al. Antioxidant effect of green tea extract in cadmium chloride intoxicated rats. Adv Appl Sci Res. 2010;1(2):9-13.

31. Lia J, Dua Y, Yanga J, et al. Preparation and Characterization of low molecular weight chitosan and chito-oligomers by a commercial enzyme. Polymer Degradation and Stability. 2005;87(3):441-448.

32. Jennings JA, Bumgardner JD. Chitosan Based Biomaterials (Vol 2). Tissue Engineering and Therapeutics. Woodhead Pub Ltd, Elsevier Science \& Technology, UK: Duxford; 2016.

33. Muzzarelli RAA, Morganti P, Morganti G, et al. Chitin nanofibrils/ chitosan glycolate composites as wound medicaments. Carbohydrate Polymers. 2007;70(3):274-284.

34. Byung KK, Shim HJ, Sang Mun H, et al. Chitin-based embolic materials in the renal artery of rabbits: Pathologic evaluation of an absorbable particulate agent. Radiology. 2005;236(1):151-158.

35. Ueno H, Mori T, Fujinaga T. Topical formulations and wound healing application of chitosan. Adv Drug Deliv Rev. 2001;52(2):105-115.

36. Varna AJ, Deshpande SVE, Kennedy JF. Metal complexation by chitosan and its derivatives: a review. Carbohydrate Polymers. 2004;55(7):227-229.

37. Zhengh LY, Zhu JF. Study on antimicrobial activity of chitosan with different molecular weights. Carbohydrate Polymers. 2003;54(4):527530 .
38. Yang X, Yang K, Wua S, et al. Cytotoxicity and wound healing properties of PVA/wschitosan/glycerol hydrogels made by irradiation followed by freeze-thawing. Radiation Physics and Chemistry. 2010;79(5):606-611.

39. Souza BWS, Cerqueira MA, Ruiz HA, et al. Effect of chitosan-based coatings on the shelf life of salmon (Salmo salar). J Agric Food Chem. 2010;58(21):11456-11462.

40. Azevedo VVC, Chaves SA, Bezerra DC, et al. Quitina e Quitosana: aplicações biomateriais. Revista Eletrônica de Materiais e Processos. 2007;2(3):27-34.

41. Balbino C, Pereira L, Curi R. Mecanismos envolvidos na cicatrização: uma revisão. Revista Brasileira de ciências Farmacológicas. 2005;41(1):27-51.

42. Becker T, Schlaak M, Strasdeit H. Adsorption of Ni(II), Zn(II) and Cd(II) by new chitosan derivatives. Reactives \& Functional Polymers. 2000;44:289-298.

43. Berger J, Reist M, Mayer JM, et al. Structure and interactions in chitosan hydrogels formed by complexation or aggregation for biomedical applications. Eur J Pharm Biopharm. 2004;57(1):35-52.

44. Viorica P, Ostafe V, Gerrit B, et al. Chitosan as a starting material for wound healing applications. Eur J Pharm Biopharm. 2015;97:417-426.

45. Campos MGN. Desenvolvimento e caracterização de membranas de quitosana para recobrimento de feridas e liberação controlada de fảrmacos. 96f. Brazil: Tese (Doutorado em Engenharia Química) Universidade Estadual de Campinas; 2007.

46. Sohn S, Gido SP. Wet-spinning of osmotically stressed silk fibroin. Biomacromolecules. 2009;10(8):2086-2091.

47. Huang X, Zhang Y, Zhang X, et al. Influence of radiation crosslinked carboxymethyl-chitosan/gelatin hydrogel on cutaneous wound healing. Mater Sci Eng C Mater Biol Appl. 2013;33(8):4816-4824.

48. Toriseva M, Kahari VM. Proteinases in cutaneous wound healing. Cell Mol Life Sci. 2009;66(2):203-224.

49. Mayol L, De Stefano D, Campani V, et al. Design and characterization of a chitosan physical gel promoting wound healing in mice. J Mater Sci Mater Med. 2014;25(6):1483-1493.

50. Chatelet C, Damour O, Domard A. Influence of the degree of acetylation on some biological properties of chitosan films. Biomaterals. 2001;22(3):261-268.

51. Theoret L. The pathophysiology of wound repair. Veterinary Clinics Equine Pratice. 2005;21(1):1-13.

52. Ishihara M, Nakanishi K, Ono K, et al. Photocrosslinkable chitosan as a dressing for wound occlusion and accelerator in healing process. Biomaterials. 2002;23(3):833-840.

53. Vinsova JE, Vavrikova E. Recent advance in drugs and prodrugs desing of chitosan. Curr Pharm Des. 2008;14(13):1311-1326.

54. Wang W, Lin S, Xiao Y, et al. Acceleration of diabetic wound healing with chitosan-crosslinked collagen sponge containing recombinant human acidic fibroblast growth factor in healing-impaired STZ diabetic rats. Life Sci. 2008;82(3-4):190-204.

55. Peng CK, Yu SH, Mi FL, et al. Polysaccharide-based artificial extracelular matrix: preparation and characterization of three-dimensional, macroporous chitosan and chondroitin sulfate composite scaffolds. Journal of Applied Polymer Science. 2006;99(5):2091-2100.

56. Albuquerque MLS, Guedes I, Alcantara Junior P, et al. Characterization of Buriti (Mauritia flexuosa L.) Oil by Absorption and Emission Spectroscopies. Journal Brazilian Chemical Society. 2015;16(6a):11131117 . 
57. Albuquerque MLS, Guedes I, Alcantra P, et al. Infrared absorption spectra of Buriti (Mauritia flexuosa L.) oil. Vibrational Spectroscopy. 2003;33(1-2):19127-19131.

58. Batista JS, Olinda RG, Medeiros VB, et al. antibacteriana e cicatrizante do óleo de buriti Mauritia flexuosa L. Cienc Rural. 2012;(1):136-141.

59. Nicholas Allain S. Manejo Sustentável e Potencial Econômico da Extração do Buriti nos Lençóis Maranhenses. Dissertação de Mestrado. Centro de Desenvolvimento sustentável. Brazil: Universidade de Brasília; 2009.

60. Jacobo FQ, Rojas MA, Reyes GI, et al. Caracterización de aceites, tortas y harinas de frutos de ungurahui (Jessenia polycarpa) y aguaje (Mauritia flexuosa Lf) de la Amazonia Peruana. Revista de la Sociedad Química del Perú. 2009;75(2):243-253.

61. Lee DW, Lim H, Chong HN, et al. Advance in chitosan material and its hybrid derivatives: a review. Open Biomaterials Journal. 2009;1:10-20.

62. Magalhães MSF, Fechine FV, Macedo RN, et al. Effect of a combination of medium chain triglycerides, linoleic acid, soy lecithin and vitamins A and E on wound healing in rats. Acta Cir Bras. 2008;23(3):262-269.

63. Sampaio MB, Carrazza LR. Manual Tecnológico de Aproveitamento Integral do Fruto e da Folha do Buriti (Mauritia flexuosa). Instituto Sociedade População e Natureza (ISPN), Brazil: Brasília DF; 2012.

64. Pianovski AR, Gonçalves Vilela AF, Da Silva AAS, et al. Uso do óleo de pequi (Caryocar brasiliensis) em emulsões cosméticas: desenvolvimento e avaliação da estabilidade física. Brazilian Journal of Pharmaceutical Sciences. 2008;42(4):249-259.
65. Saraiva NA. Manejo Sustentável e Potencial Econômico da Extração do Buriti nos Lençóis Maranhenses. Dissertação de Mestrado, Centro de Desenvolvimento sustentável, Brazil: Universidade de Brasília; 2009.

66. MartinsI EAN, InvernizziI MS, Nogueira Campos MG, et al. Emprego de membrana de quitosana em feridas cutâneas induzidas experimentalmente em eqüinos. Ciência Rural. 2013;43(10):1824-1830.

67. Manhães LRT. Caracterização da polpa de buriti (Mauritia flexuosa Mart): um potente alimento funcional. Brazil: Universidade Federal Rural do Rio de Janeiro; 2007. 78 p.

68. Sampaio MB, Schmidt IB, Figueiredo IB. Harvesting effects and population ecology of the buriti palm (Mauritia flexuosa $\mathrm{L} f$ Arecaceae) in the Jalapão Region, Central Brazil. Economic Botany. 2008;62(2):171181.

69. Manhães LRT, Sabaa Srur AUO. Centesimal composition and bioactive compounds in fruits of buriti collected in Pará. Ciênc. Tecnol. Aliment. 2011;31(4):856-863.

70. Zanatta CF, Ugartondo V, Mitjans M, et al. Low cytotoxicity of creams and lotions formulated with Buriti oil (Mauritia flexuosa) assessed by the neutral red release test. Food Chem Toxicol. 2008;46(8):2776-2781.

71. Zanatta CF, Ugartondo V, Mitjans M, et al. Photoprotective potential of emulsions formulated with Buriti oil (Mauritia flexuosa) against UV irradiation on keratinocytes and fibroblasts cell lines. Food Chem Toxicol. 2010;48(1):70-75. 